\title{
CORRELATION BETWEEN VISUAL AND KINESTHETIC SPATIAL AFTEREFFECTS
}

\author{
A. A. LANDAUER, ${ }^{1}$ G. SINGER, \\ University of Sydney \\ AND R. H. DAY \\ Monash University
}

\begin{abstract}
A kinesthetic and visual aftereffect in judgment of horizontality was found for $202 \mathrm{Ss}$ in paired balanced trials using the method of adjustment. Adjustment times were also measured. The correlation between the 2 aftereffects was reduced but nevertheless significant after allowance had been made by partial correlation for adjustment times in the 2 tasks. This finding is contrary to that of earlier experiments in which allowance was not made for adjustment times.
\end{abstract}

The cortical satiation theory of spatial aftereffects (Köhler \& Wallach, 1944) has been extended by others to include a notion of differential satiability between normal and certain psychopathological conditions (Klein \& Krech, 1952; Wertheimer, 1955) and between individuals with different personality characteristics (Eysenck, 1955). Spatial aftereffects following prolonged stimulation have been used, therefore, to compare cortical modifiability between these various behavioral states following prolonged stimulation. An implication of differential satiation is a positive correlation between the magnitude of spatial aftereffects in different sensory modalities. If, for example, a certain psychopathological condition is associated with restricted cortical satiability, then it would be expected that spatial aftereffects would be smaller in magnitude than for normal $S \mathrm{~s}$ in both vision and kinesthesis. So far investigations have failed to confirm significant positive correlations between visual and kinesthetic aftereffects (Gardner, 1961; McEwen \& Rodger, 1960; Spitz \& Lipman, 1960).

Since hoth visual kinesthetic spatial

${ }^{1}$ Now at the University of Western Australia, Perth, Western Australia. aftereffects dissipate exponentially over time (Hammer, 1949; Oyama, 1953; Singer \& Day, 1965) and, further, are most frequently investigated using the method of adjustment involving a timedelay aftercessation of stimulation, their magnitude will vary as a function of the time $S$ takes to complete the adjustment. Lack of correlation between aftereffects in two modalities could, therefore, be attributable to differences in adjustment times. This would be more likely to occur when the two tasks demand different degrees of fineness and accuracy so that adjustments in one takes substantially more time than adjustments in the other. Alternatively positive correlation could be due to similarities in adjustment time. An $S$ making quick adjustments would show greater aftereffects than one making slow adjustments. In only one of the studies mentioned above (McEwen \& Rodger, 1960) was adjustment time controlled and so far no account has been taken of the contribution of this factor to the relationship between aftereffects in different modalities.

The purpose of this experiment was to establish the correlation between a kinesthetic and visual spatial after- 
TABLE 1

Means and $S D$ S OF Aftereffects (DEGREes) AND ADJUSTMENT Times (SEC.)

\begin{tabular}{l|r|r}
\hline \multicolumn{1}{|c|}{ Variables } & \multicolumn{1}{c|}{$M$} & \multicolumn{1}{c}{$S D$} \\
\hline Visual Aftereffect & 2.16 & 1.19 \\
Kinesthetic Aftereffect & 4.72 & 2.38 \\
Visual Adjustment Time & 14.04 & 15.62 \\
Kinesthetic Adjustment Time & 31.86 & 22.24 \\
\hline
\end{tabular}

effect for essentially similar tasks involving visual and kinesthetic judgments of horizontality following appropriate stimulation by a slanted stimulus object. Adjustment times have been taken into account by means of partial-correlation procedures.

\section{Method}

Subjects.-There were 92 male and 110 female $S$ s with a mean age of 19.9 yr. recruited from introductory classes in psychology.

Apparatus.-The apparatus already described in detail (Day \& Singer, 1964) consisted of a pivoted circular target with luminescent bars for inducing and measuring the visual aftereffect and a pivoted wooden bar for the kinesthetic aftereffect. Both these could be adjusted by $S$ to the apparent horizontal by means of manually operated rotary controis.

Procedure.-The visual target was fixated at its center for $90 \mathrm{sec}$. while slanted $15^{\circ}$ after which $S$ adjusted it to appear horizontal. The bar was similarly adjusted after side to side movement of the extended

TABLE 2

INTERCORRELATIONS AMONG THE FOUR VARIABLES IN TABLE 1

\begin{tabular}{l|r|r|r}
\hline & $\begin{array}{c}\text { Kinesthetic } \\
\text { Aftereffect }\end{array}$ & $\begin{array}{c}\text { Visual } \\
\text { Adjustment } \\
\text { Time }\end{array}$ & $\begin{array}{c}\text { Kinesthetic } \\
\text { Adjustment } \\
\text { Time }\end{array}$ \\
\hline $\begin{array}{c}\text { Visual } \\
\text { Aftereffect } \\
\begin{array}{c}\text { Kinesthetic } \\
\text { Aftereffect }\end{array}\end{array}$ & $.303^{* *}$ & -.189 & -.173 \\
$\begin{array}{c}\text { Visual Ad- } \\
\text { justment } \\
\text { Time }\end{array}$ & -.111 & $-.304^{* *}$ \\
\hline
\end{tabular}

$* * p<.01$.

$* * * p<.001$ arm and hand across its $15^{\circ}$ slanted edge while $S$ was blindfolded. Both scales were modified from earlier experiments to permit readings to the nearest $0.1^{\circ}$.

Each $S$ underwent four trials (two visual and two kinesthetic) consisting of $90 \mathrm{sec}$. stimulation and a posttest. The order in which the pair of visual trials and kinesthetic trials occurred alternated from $S$ to $S$. Adjustment times from cessation of stimulation to completion of adjustment were timed with a stopwatch.

The aftereffect was determined using a method developed by Wenderoth $(1964)^{2}$ which is applicable in the case of paired balanced trials. In the context of this experiment pairs of trials were balanced when the inducing object or figure was slanted from the horizontal in one direction on the first trial of a pair and in the opposite direction to the same extent on the second trial. Although this procedure provides some control over cumulative effects which might have occurred if stimulation were always in the same direction, incomplete dissipation of an aftereffect from one trial would be reflected in the pretest setting of the second. With balanced trials this would result in a spurious inflation of the mean aftereffect. Wenderoth has shown that the mean difference between the two pretests when subtracted from the mean aftereffect from two balanced trials eliminates this inflation and showed algebraically that the same value is arrived at by taking half the algebraic difference between two posttest settings of the test object or figure.

\section{Results and Discussion}

In Table 1 are shown the means and standard deviations of aftereffects and adjustment times and in Table 2 the product-moment correlations between the four variables. These data indicate that there is a significant correlation (.303) between the two aftereffects.

The correlation (.668) between adjustment times for the two tasks, however, suggests that the relationship between the aftereffects may be due in part to this variable. When the effect due to adjustment times is corrected

2 This procedure for deriving an aftereffect was used by Gibson and Bergman (1959) but the rationale was not given. 
by partial-correlation procedures ( $\mathrm{Mc}$ Nemar, 1962), the correlation between kinesthetic and visual effects is reduced to $.262(p<.01)$, which shows that there is a significant correlation between the aftereffects in the two modalities which is not entirely due to similarities in adjustment time.

These findings based on a substantial group of $S s$ again draw attention to the importance of adjustment time as a factor in measuring the spatial aftereffect using the adjustment method and lend support to the notion of a general underlying process. The lack of correlation between aftereffect in the two modalities in earlier studies may be attributable to differences in adjustment times due to task differences.

\section{REFERENCES}

DAy, R. H., \& Singer, G. Spatial aftereffects within and between kinesthesis and vision. J. exp. Psychol., 1964, 68, 337-343.

EYSENCK, H. J. Cortical inhibition, figural aftereffects and theory of personality. J. abnorm. soc. Psychol., 1955, 51, 94-106.

GARDNER, R. W. Immediate and residual figural aftereffects in kinesthesis. Amer. J. Psychol., 1961, 74, 457-461.

Gibson, J. J., \& Berganan, R. The negative aftereffect of perception of a surface slanted in the third dimension. Amer. J. Psychol., $1959,3,364-374$.

HAMMER, E. R. Temporal factors in figural aftereffect. Amer. J. Psychol., 1949, 62, 337-354.

$K_{\text {LEIN, }}$ C. S., \& KRECH, D. Cortical conductivity in the brain injured. J. Pers., 1952, 21, 118-148.

KöHler, W., \& Wallach, H. Figural aftereffects: An investigation of visual processes. Proc. Amer. Phil. Soc., 1944, 88, 269-357.

McEwen, P., \& Rodger, R. S. Some individual differences in fioural aftereffects. Brit. J. Psychol., 1960, 51, 1-8.

McNemar, Q. Psychological statistics. (3rd ed.) New York, Wiley, 1962.

Oyama, T. Experimental studies of figural aftereffects: I. Temporal factors. Jap. J. Psychol., 1953, 23, 239-254.

SingER, G., \& DAY, R. H. Temporal determinants of a kinesthetic aftereffect. $J$. exp. Psychol., 1965, 69, 343-348.

Spitz, H. H., \& Lipman, R. S. Reliability and intercorrelation of individual differences on visual and kinesthetic figural aftereffects. Percept. mot. Skills, 1960, $10,156-166$.

WERTHEIMER, M. Figural aftereffects as a measure of metabolic efficiency. J. Pers., $1955,24,56-57$.

WENDEROTH, P. M. A definition of aftereffect to be used in the case of paired balanced trials. Paper read at the Sixth Canberra Symposium on Perception, Canberra, 1964.

(Received October 16, 1965) 